\title{
Identity Politics as a Comparative Poetics
}

\author{
GRETA GAARD
}

This is an intervention. A message from that space in the margin that is a site of creativity and power, that inclusive space where we recover ourselves, where we move in solidarity to erase the category colonized/colonizer. Marginality as site of resistance. Enter that space. Let us meet there. Enter that space. We greet you as liberators.

—bell hooks, "marginality as site of resistance"

As notions of diversity and multiculturalism have become central to most academic discussions, they have raised the related question of identity politics. I approach this question as a woman, as a white, middle-class lesbian. The question of identity concerns me when I learn that a male colleague has been assigned a course on women's literature. I am also concerned when I see that heterosexual women are writing lesbian feminist criticism. At the same time, I am eager to teach courses on black women's novels when I learn that there are no such courses offered at my university, and no black women faculty available to teach them. Finally, as I work on course proposals for classes in lesbian and gay literature, and an introduction to queer culture, my authority to write, teach, or speak as a lesbian is called into question by my community when it learns that I have also chosen men as sexual partners.

In each of these instances I am concerned with developing a politics of identity which accounts for the particular authority of embodied subjects, but without falling prey to essentialist notions of identity which lead one group to excommunicate another. I am interested in a politics of identity which encourages coalition building across identities while affirming the uniqueness of each embodied subject. For these reasons I want to explore the discourse now evolving around the relation of identity politics and bisexuality. As a literary scholar and teacher, I see the identity of bisexuality as inherently comparative, and believe this perspective can be used to raise new questions in literary theory. 
Identity politics can be defined as the practice of claiming one's identity as a suitable location from which theory can be made, and as a suitable location for creating a political agenda. The question is: What is identity? How can identity be defined? To answer this question I first briefly survey the essentialism-versus-constructionism debates which have taken place in the lesbian and gay communities. I then offer an alternative theory of bisexuality as a basis for identity politics and a location for comparative criticism. I believe the two have much to offer each other: theories of both comparative literature and bisexuality have arisen from a location of exile, and both are concerned with the problems of translation. Finally, to demonstrate the potential uses of such a theory, I use it to consider Virginia Woolf's Orlando.

Within the gay and lesbian communities, essentialism has played an important role. By assuming that all lesbians have something in common, and by extension that all lesbians and gays have something in common, the gay and lesbian community at large has been able to advance important political agendas for improving our conditions. ${ }^{1}$ But within the community essentialism has become a kind of police force. Susie Bright, co-founder of the lesbian sex magazine On Our Backs, has expressed concern about "the deployment of rigid sexual categories, not only by the Right, but also within our own communities, where investments in the stability, internal coherence, and uniqueness of lesbian identity have not only obscured sexual differences, but generated an active resistance to knowing what we fantasize, desire, do, and think."2 Similarly, Diana Fuss observes that while "current lesbian theory is less willing to question or to part with the idea of a lesbian essence' and an identity politics based on this shared essence," gay male theorists "have been quick to endorse the social constructionist hypothesis and to develop more detailed analyses of the historical construction of sexualities." Her explanation for this difference is persuasive: "If the adherence to essentialism is a measure of the degree to which a particular political group has been culturally oppressed... then the stronger lesbian endorsement of identity and identity politics may well indicate that lesbians inhabit a more precarious and less secure subject position than gay men." ${ }^{\prime 3}$ Whereas gay men have only one

'Rebecca Shuster, "Sexuality as a Continuum: The Bisexual Identity," in Lesbian Psychologies: Explorations and Challenges, ed. Boston Lesbian Psychologies Collective (Chicago: University of Illinois Press, 1987), 56-71.

2Biddy Martin, "Sexual Practice and Changing Lesbian Identities," unpublished ms.

${ }^{3}$ Diana Fuss, Essentially Speaking: Feminism, Nature, and Difference (New York: Routledge, Chapman \& Hall, 1989), 98. 
strike against them (being gay), lesbians have two strikes (being lesbian and being women); the number of strikes increases if the person in question is, for example, differently abled or of color.

The lesbian theorists Monique Wittig and Adrienne Rich refuse to reduce lesbianism to an exclusively sexual, genital act. But the definitions they propose instead seem almost contradictory. For example, in "The Straight Mind," Wittig asserts that "lesbians are not women" but rather a third sex which subverts the false dichotomy between heterosexual and homosexual; conversely, in "Compulsory Heterosexuality and Lesbian Existence," Rich affirms that "all women are lesbians," existing along a continuum that includes "many ... forms of primary intensity between and among women." ${ }^{\prime 4}$ As Fuss observes, if Wittig's notion of lesbian identity is too exclusive, Rich's is surely too inclusive. Neither description accounts for specific sexual practices of individual women.

To the question "What is a lesbian?" constructionism seems to provide a more descriptive answer. The earliest description of sexuality as a spectrum, the Kinsey scale, rates sexuality along a continuum with $o$ being exclusively heterosexual, 6 being exclusively homosexual, and 3 being equally heterosexual and homosexual. ${ }^{5}$ More recently, Michael Shively and John De Cecco define four psychological components of sexual identity, which include biological sex, gender identity (formed by age three), social sex role (comprising masculine or feminine behaviors), and sexual orientation (self-description). ${ }^{6}$ Beth Zemsky also uses this scale, adding a fifth component, sexual practices. ${ }^{7}$ According to these definitions, a person may be born a woman (biological sex), appear to be feminine (gender identity), but behave in ways considered masculine (social sex role), describe herself as a lesbian (sexual orientation), and have sexual relations with men and women (sexual practice). Which of these components constitutes the "identity" from which to build political strategy? Would the person just described be seen as lesbian or bisexual? The prominence of any one component of sexual identity may depend on the specific political context.

\footnotetext{
${ }^{4}$ See Monique Wittig, "The Straight Mind," in Out There: Marginalization and Contemporary Cultures, ed. Russell Ferguson, Martha Gever, Trinh T. Minh-ha, and Cornel West (New York: New York Museum of Contemporary Art, 1990), 51-58; and Adrienne Rich, "Compulsory Heterosexuality and Lesbian Existence," in Blood, Bread, and Poetry: Selected Prose, 1979-1985 (New York: Norton, 1986), 23-75.

${ }^{5}$ For a variety of scales defining sexuality, see Loraine Hutchins and Lani Kaahumanu, eds., Bi Any Other Name: Bisexual People Speak Out (Boston: Alyson, 1991).

'Michael G. Shively and John P. De Cecco, "Components of Sexual Identity," Journal of Homosexuality, 3.1 (Fall 1977): 41-48.

"Beth Zemsky, "Stonewall Remembered," GLCAC OutFront 2.4 (Summer 1991): 1, 3.
} 
The overall purpose, it must be remembered, for defining an identity in such instances is to create a place from which to develop a political agenda, and to specify the position of the theorist. But if constructionism is most helpful in defining identity, essentialism has proven most useful as a political strategy. Amanda Udis-Kessler writes: "While constructionism may represent the better description of human sexuality, the very elements which make lesbian/gay communities strong today-perhaps which make them possible as communities at all-are essentialist." ${ }^{\prime 8}$ Theories of antiessentialism, by erasing the possibility of essence, also deprive subjects of a platform from which to create political agendas or build coalitions. Defining what counts as a position for building theory becomes immediately a politicized act. In the history of feminism, women have repeatedly defended their authority to speak based on their unique location as women. "The difference between feminists and antifeminists strikes me as precisely this," writes Linda Alcoff, "the affirmation or denial of our right and our ability to construct, and take responsibility for, our gendered identity, our politics, and our choices." ${ }^{\prime 9}$

Poststructuralists such as Lacan, Derrida, and Foucault argue, according to Alcoff, that "the self-contained, authentic subject conceived by humanism to be discoverable below a veneer of cultural and ideological overlay is in reality a construct of that very humanist discourse." Lacan uses psychoanalysis, Derrida uses grammar, and Foucault uses the history of discourses to deconstruct our concept of the subject's having an essential identity. Each arrives at the conclusion that there is no essential core: "For the post-structuralist, race, class, and gender are constructs and, therefore, incapable of decisively validating conceptions of justice and truth because underneath there lies no natural core to build on or liberate or maximize. Hence, once again, underneath we are all the same." ${ }^{\prime 10}$ Such arguments cannot provide a platform for grounding a feminist politics: if there is no "real" difference between women and men, says Alcoff, there can be no basis for an agenda of "women's needs." Teresa de Lauretis agrees: "If 'woman' is a fiction, a locus of pure difference and resistance to logocentric power, and if there are no women as such, then the very issue of women's oppression would appear to be obsolete and feminism itself would have no reason

\footnotetext{
${ }^{8}$ Amanda Udis-Kessler, "Bisexuality in an Essentialist World: Toward an Understanding of Biphobia," in Bisexuality: A Reader and Sourcebook, ed. Thomas Geller (Hadley, Mass.: Times Change Press, 1990), 51-63.

'Linda Alcoff, "Cultural Feminism versus Post-Structuralism: The Identity Crisis in Feminist Theory," Signs 13 (Spring 1988): 432.

${ }^{10}$ Ibid., 415, 432.
} 
to exist (which, it may be noted, is a corollary of poststructuralism and the stated position of those who call themselves 'post-feminists')."11

Through arguments such as these, constructionism leads feminists (along with lesbians and bisexuals) to a position of having to defend our very existence. But this is a false position. Shane Phelan writes: "We do not need to prove that we exist, in the manner of metaphysics, which is to prove that we have the right to exist. We do exist. We live our lives, inescapably, with existing others. To justify this by defining, by ontologizing, by tracing descent, is to suggest that our present existence is open to dispute." 12 Our existence, however, cannot be articulated through an appeal to the body or to our unique experiences, for a variety of reasons. "Bodily experiences may seem self-evident and immediately perceptible but they are always socially mediated," Fuss observes; for this reason "we need to be extremely wary of the temptation to make substantive claims on the basis of the so-called 'authority' of our experiences."13 Gayle Rubin reminds us that "we never encounter the body unmediated by the meanings that cultures give to it.... It is impossible to think with any clarity about the politics of race or gender as long as these are thought of as biological entities rather than as social constructs. Similarly, sexuality is impervious to political analysis as long as it is primarily conceived as a biological phenomenon or an aspect of individual psychology."14 If both essentialism and constructionism are flawed, perhaps the solution lies in a strategy of using essentialist rhetoric while simultaneously problematizing the subject.

Rich, in "Notes toward a Politics of Location," remarks that "perhaps we need a moratorium on saying 'the body.' For it's also possible to abstract 'the' body. When I write 'the body,' I see nothing in particular. To write 'my body' plunges me into lived experience, particularity: I see scars, disfigurements, discolorations, damages, losses, as well as what pleases me." In place of the essentialist, universalizing determiner "the," Rich suggests using the constructionism of the pronoun "my" as a way to locate bodily experiences historically in terms of race, class, gender, and sexuality. As a means of defining identity, then, Rich advises us to ask not "What is a woman?" but rather "Where, when, and

\footnotetext{
"Teresa de Lauretis, "Upping the Anti (sic) in Feminist Theory," in Conflicts in Feminism, ed. Marianne Hirsch and Evelyn Fox Keller (New York: Routledge, 1990), 255-70.

${ }^{12}$ Shane Phelan, Identity Politics: Lesbian Feminism and the Limits of Community (Philadelphia: Temple University Press, 1989), 158.

${ }^{13}$ Fuss, Essentially Speaking, 25.

${ }^{14}$ Gayle Rubin, "Thinking Sex: Notes for a Radical Theory of the Politics of Sexuality," in Pleasure and Danger: Exploring Female Sexuality, ed. Carole S. Vance (Boston: Routledge \& Kegan Paul, 1984), 276-77.
} 
under what conditions have women acted and been acted on, as women?" In posing this question, Rich defines identity politics for women as the "politics of asking women's questions. We are not 'the woman question' asked by somebody else; we are the women who ask the questions." 15

"Woman" or "lesbian" in this analysis becomes not an essence but a location for the intersection of identities at a given historical moment. In this way, writes Alcoff, "the position that women find themselves in can be actively utilized (rather than transcended) as a location for the construction of meaning, a place from where meaning is constructed, rather than simply the place where a meaning can be discovered (the meaning of femaleness)." ${ }^{\prime 16}$ Identity becomes not a fixed essence but rather a social construction, a product of the intervening forces of a subject's location in terms of class, color, age, physical ability, gender, sexual orientation, historical moment.

Censorship occurs when only certain locations are authorized as appropriate points for making theory. The issue is not only which theory counts as theory, as knowledge, but more than that, which locations count as sites for the production of theory. As a kind of test case I would offer the earlier question about the role of bisexual practices in defining identity.

Characterized and caricatured as fence-sitters, bisexuals have been seen, and have seen themselves, as having "no place" from which to make theory. Defined as people in the process of moving from one sexual location to another, bisexuals have only recently begun to claim that movement itself as a suitable location for theory. In claiming an identity which is not one of either/or but rather one of both/and, they reject what they see as a patriarchally inscribed dualism, heterosexuality/homosexuality.

Questions of identity group formation often rely on the establishment of boundaries, on defining an identity in opposition to other identity groups. As Andrew Parker and others argue: "National identity is determined not on the basis of its own intrinsic properties but as a function of what it (presumably) is not.... But the very fact that such identities depend constitutively on difference means that nations are forever haunted by their various definitional others. ${ }^{\prime 17}$ Diana Fuss articulates much the same point: "To the extent that identity always con-

${ }^{15}$ Adrienne Rich, "Notes toward a Politics of Location," in Blood, Bread, and Poetry, 216.

${ }^{16}$ Alcoff, "Cultural Feminism," 434.

${ }^{17}$ Andrew Parker, Mary Russo, Doris Sommer, and Patricia Yaeger, eds., Nationalisms and Sexualities (New York: Routledge, 1992), 5. 
tains the specter of non-identity within it, the subject is always divided and identity is always purchased at the price of the exclusion of the Other, the repression or repudiation of non-identity."18 But feminists have observed that this oppositional way of defining the self as separate is a male gendered trait, whereas defining a self-in-relationship is a female gendered trait. ${ }^{19}$ So what are the implications of these gendered processes of identity formation when applied to identity politics? If the two most dominant boundaries of identity are nationalisms and sexualities, as some may claim, ${ }^{20}$ what are the implications for a bisexual theory of identity politics? For unlike the clearly delineated boundaries of nationalism, or the hetero-homo divide, in which the identity of self or group is established in clear distinction against a "them" of opposition, the boundaries of bisexual identity formation are everywhere and nowhere. Just as there has been no clear "us," there are also no clear "them"s. Bisexual identity has involved a process of continual repositioning between fixed boundaries of sexualities, a process in which bisexuals are continually made to feel like a "them" no matter where they are located.

The problem is magnified by the fact that both the heterosexual and homosexual communities have a distinct culture, if culture can be defined as having a unique art, literature, music, and theater. ${ }^{21}$ I would also add to these language and geographic space, thus underscoring the connections between sexualities and nationalisms. The problem of "seeing bisexual" then becomes the problem of being continually in exile, an outsider in both heterosexual and homosexual cultures.

Bisexuality means more than holding dual citizenship, though many critics of bisexuality, who conceptualize it in this way, censure bisexuals for enjoying undue advantages-the pleasures of homosexuality and the privileges of heterosexuality. The true allegiance of bisexuals is continually called into question; more than exiles, in fact, bisexuals are seen as double agents in a war of dichotomized sexualities. In this way bisexuality is located on the boundaries of sexual discourse and in the margins of lesbian or heterosexual feminist literary criticism. As a marginalized perspective, bisexuality has the potential to be inherently feminist, inherently comparative.

${ }^{18}$ Fuss, Essentially Speaking, 103.

${ }^{19}$ See, for example, Nancy Chodorow, The Reproduction of Mothering: Psychoanalysis and the Sociology of Gender (Berkeley: University of California Press, 1978); and Carol Gilligan, In a Different Voice: Psychological Theory and Women's Development (Cambridge: Harvard University Press, 1982).

${ }^{20}$ See Parker et al., Nationalisms and Sexualities.

${ }^{21}$ This definition is offered by Bonnie Zimmerman in The Safe Sea of Women: Lesbian Fiction, 1969-1989 (Boston: Beacon, 1990). 
This form of "dual citizenship" is addressed in terms of color and nationality by Gloria Anzaldúa, who writes of "the New Mestiza" in Borderlands/La Frontera, and of the difficulty of "living on borders and in margins, keeping intact one's shifting and multiple identity and integrity." For Anzaldúa identity is defined in opposition to something else: "Borders are set up to define the places that are safe and unsafe, to distinguish $u s$ from them. A border is a dividing line, a narrow strip along a steep edge. A borderland is a vague and undetermined place created by the emotional residue of an unnatural boundary. It is in a constant state of transition. The prohibited and forbidden are its inhabitants." 22 But, like the identity of bisexuals, the identity of the New Mestiza belongs to neither nationality; the New Mestiza is neither "us" nor "them." This position, instead of being a site for erasure and invisibility, may provide possibilities for comparative readings and coalition building across perspectives. Feminists have frequently spoken of the utility of margins and marginalized viewpoints in constructing more inclusive political agendas. It is in the margins that coalition building begins, through the very experiences of the racial, cultural, and/or sexual mestizas.

According to bell hooks, marginality is "much more than a site of deprivation"; it is "the site of radical possibility, a space of resistance." Marginality can be seen as "a central location for the production of a counter hegemonic discourse." But this resistance must be spoken in a language that is not the language of the colonizer: "One can only say no, speak to the voice of resistance, because there exists a counter language. While it may resemble in ways the colonizer's tongue, it has to undergo a transformation." ${ }^{23}$ Like the language of the Mestiza, the language of the sexually marginalized appropriates and mixes words to create new meanings. But, as Judy Grahn writes in Another Mother Tongue, "there has been no acceptance and exploration of the Gay context that would allow our subterranean slang words to enter the world of dictionaries." Grahn's exploration of gay language reveals "parameters and characteristics of homosexual culture" that are not accessible from a heterosexual perspective. ${ }^{24}$ It is, however, precisely because the words are not placed in their gay context that their meaning is inaccessible. Writing about the same problem, Paula Gunn Allen explains that those who attempt to understand Native American cere-

\footnotetext{
${ }^{22}$ Gloria Anzaldúa, Borderlands/La Frontera: The New Mestiza (San Francisco: Spinsters/ Aunt Lute, 1987), 2, 3.

${ }^{23}$ bell hooks, "Marginality as Site of Resistance," in Ferguson et al., Out There, 341, 342.

${ }^{24}$ Judy Grahn, Another Mother Tongue: Gay Words, Gay Worlds (Boston: Beacon, 1984), xiii, xiv.
} 


\section{Greta Gaard}

monial literature apart from its cultural context will be unable to do so. ${ }^{25}$ Using a similar rationale, bisexual theorists have begun to reject the very word bisexual, arguing that because it originates in the context of heterosexual/homosexual discourse, it retains and embodies an oppressive ideology.

Paula Rust has discovered at least four different ways in which bisexual and lesbian women define bisexuality, all of which remain within the boundaries of the heterosexual/homosexual discourse. Some argue that bisexuality is nonexistent, and women who identify themselves as bisexual are really "confused" or are in transition to becoming lesbians. Others see bisexuality as a combination of heterosexuality and homosexuality, a kind of dual membership in two societies. Relatively few women see sexuality as a continuum, with bisexuality falling somewhere between heterosexual and lesbian sexualities. And finally, still others seem to conceptualize sexuality as a trichotomy, with bisexuality as "a third, distinct sexual orientation." Rust, in "Who Are We and Where Do We Go from Here?" rejects each of these definitions as perpetuating a fundamental homosexual/heterosexual dichotomy, and calls for a new word to contain a new conceptualization: "If we wish to challenge the hegemonic homosexual/heterosexual dichotomy, assert the existence of bisexuality and emphasize the commonality of all people, we must communicate this message in a language that is intelligible and effective in the current political climate. Conceptualizing bisexuality as a qualitatively different form of sexuality ... offers us the opportunity to do exactly that." Rust rejects the word bisexual because it "embodies the negative definition" of bisexuals in that "the emphasis remains on the biological sex characteristics of potential romantic partners. Although we argue that we do not choose our partners based upon their biological sex, we still define ourselves with a word that refers to the biological sex of our partners." Rust, who prefers "to banish the concept of partner sex from our vocabulary of self-identity," suggests "pansensual" as a term that describes an individual's sexual identity in a way that acknowledges sexuality as a wholistic experience more than a merely genital one. Her awareness of the implications of this new description of identity can be seen in her choice of words: she compares the new identity and experience to being in a foreign country, using foreign currency and a foreign language; and she discusses this revised sexual identity in terms of a geographic "territory." 26 Rust's

\footnotetext{
${ }^{25}$ See Paula Gunn Allen, The Sacred Hoop: Recovering the Feminine in American Indian Traditions (Boston: Beacon, 1986).

${ }^{26}$ Paula C. Rust, "Who Are We and Where Do We Go from Here? Conceptualizing
} 
definition of sexual identity as a personal characteristic that can no longer be unquestioningly defined in terms of partner sex may be a useful perspective for providing a comparative reading of Orlando.

The usefulness of a bisexual (or "pansensual") literary criticism can be seen by examining just one author and one text: Virginia Woolf's Orlando. ${ }^{27}$ Woolf's sexual identity has been a topic of interest to literary critics for many years. (It is interesting to recall that, just as her sexual identity is difficult to define, so too is her nationality: in Three Guineas Woolf writes that as a woman, she has no country.) Whereas Quentin Bell's biography emphasizes the importance of Woolf's relationship with Vita Sackville-West, Louise DeSalvo's study reveals Woolf as a woman severely traumatized by incest and basically incapable of sexual relations of any kind. ${ }^{28}$ Although she enjoyed a supportive and enduring relationship with her husband, Woolf's sole sexual relationship was with Vita. As Ellen Rosenman observes, though Woolf lived in an era that equated sexual activity with sexual identity, Woolf made no such equation for herself..$^{29}$ The postmodern fragmentation of identity, as in Shively and DeCecco's "Components," along with Rust's definition of the pansensual, may offer a more accurate (though anachronistic) means of describing Woolf's sexual identity as quite distinct from her sexual practices.

But as every literary scholar knows, authors are not to be confused with texts, and Virginia Woolf's sexual identity is not Orlando's. Perhaps the climate of cultural feminism in the 1980's is responsible for the number of literary critics battling to claim Orlando as a lesbian text-as if lesbianism were somehow the quintessential state of feminism-and Woolf as the ultimate feminist literary foremother. But, like Woolf herself, or Woolf's friend and lover, Vita, after whom Orlando is modeled, the character cannot be reduced to the binary confines of heterosexuality/homosexuality.

Orlando's identity both transcends and permeates the various locations of gender, sex, and sexuality through which s/he is repositioned. Orlando begins the novel as a "boy" of sixteen (though of ambiguous

Bisexuality," in Closer to Home: Bisexuality and Feminism, ed. Elizabeth Reba Weise (Seattle: Seal, 1992), 291, 297-301.

${ }^{27}$ Virginia Woolf, Orlando (New York: Harcourt Brace, 1928); subsequent references are cited in the text.

${ }^{28}$ Quentin Bell, Virginia Woolf: A Biography (New York: Harcourt Brace Jovanovich, 1972); Louise DeSalvo, Virginia Woolf: The Impact of Childhood Sexual Abuse on Her Life and Work (Boston: Beacon, 1989).

${ }^{29}$ Ellen Bayuk Rosenman, "Sexual Identity and A Room of One's Own: 'Secret Economies' in Virginia Woolf's Feminist Discourse," Signs 14 (1989): 648. 
gender) who is attracted to Sasha without knowing her biological sex, sex role, gender identity, or sexual orientation: "[Orlando] beheld ... a figure, which, whether boy's or woman's, for the loose tunic and trousers of the Russian fashion served to disguise the sex, filled him with the highest curiosity.... [An] extraordinary seductiveness... issued from the whole person" (37). Later, Orlando realizes that what he feels for the Archduchess Harriet is not love but lust (116-17), and he reacts by marrying Rosina Pepita, a Gypsy dancer, then falling into a deep trance, and awakening as a woman when the trumpets blast "The Truth!" (137). Does the call of the trumpets signal that Orlando is "really" a woman, and has "really" been a woman all along? Are we to understand that there is some underlying essence to Orlando? Or is this call for "truth" yet another theatrical shift in the performance of gender?

As the narrator remarks, Orlando's alteration is disturbing only to others. Oblivious to any difficulties associated with this sex change, Orlando departs to live with the Gypsies, but on returning to English society realizes the enormity of the problem caused by this shift in outward identity. In each case the "problem" is related to clothing. In cultures that do not distinguish gender through clothing (the Russian and the Gypsy), Orlando is largely untroubled; in English culture, which insists on such distinctions, both the clothing and the gender roles become restrictive: "It was not until she felt the coil of skirts about her legs and the Captain offered, with the greatest politeness, to have an awning spread for her on deck that she realised with a start the penalties and the privileges of her position" (153). Orlando first delights in gender play, then reviles both gender roles, and finally concludes that she loves Sasha better as a woman because now Orlando understands Sasha's own experiences. Does this section of the narrative mean to imply that homosexual love is preferable to heterosexual since it is based on a more complete way of knowing the beloved? When Orlando returns home and is greeted by her household, it is the animals who best recognize her through her costumery of gender: "No one showed an instant's suspicion that Orlando was not the Orlando they had known. If any doubt there was in the human mind the action of the deer and the dogs would have been enough to dispel it, for the dumb creatures, as is well known, are far better judges both of identity and character than we are" (170). Of course, Orlando is not alone in manipulating the wardrobe of identity: the next day Orlando is visited by the Archduchess Harriet, who reveals herself to be the Archduke Harry.

Orlando's new biological identity has affected her gender: "She was becoming a little more modest, as women are, of her brains, and a little 
more vain, as women are, of her person" (187). The narrator credits this to the change in clothing-and certainly clothing is the gendered construct of a particular cultural and historical location ${ }^{30}$-speculating that "it is clothes that wear us and not we them ... they mould our hearts, our brains, our tongues to their liking" (188). But the narrator does not see the culture as controlling Orlando; rather, "clothes are but a symbol of something hid deep beneath. It was a change in Orlando herself that dictated her choice of a woman's dress and of a woman's sex" (188). Not until sex reassignment surgery could such a "choice" be made except in fiction. Would Orlando be better described, then, as a transsexual?

But to ask this question presupposes a unity and uniformity among the components of sexual identity in such a way that they are organized according to a heterosexual paradigm. The narrator suggests something quite the contrary: "In every human being a vacillation from one sex to the other takes place, and often it is only the clothes that keep the male or female likeness, while underneath the sex is the very opposite of what it is above. Of the complications and confusions which thus result every one has had experience" (189). Exasperated with the intellectual life, Orlando cross-dresses-or puts on her own old clothesand picks up a prostitute. The way the prostitute behaves toward Orlando calls up in her the feelings she had as a man: "To feel her hanging lightly yet like a suppliant on her arm, roused in Orlando all the feelings which become a man. She looked, she felt, and she talked like one" $^{\prime \prime}(216-17)$. Only the biological identity of Orlando is now that of a woman. Does this mean that Orlando is a butch lesbian? A transgendered person? Or simply in drag? Through the prostitute Nell, Orlando meets a whole society of prostitutes, and enjoys their company very much. One might recall Joan Nestle's essay "Lesbians and Prostitutes: An Historical Sisterhood" and wonder if this confirms Orlando's identity as a lesbian. ${ }^{31}$ But Orlando's identity cannot be so easily confined. The narrator tells us: "Her sex changed far more frequently than those who have worn only one set of clothing can conceive. ... From the probity of breeches she turned to the seductiveness of petticoats and enjoyed the love of both sexes equally" (221). What is meant by "sex"? Biological sex? Sex role? Sexual identity? What kind of identity does Orlando assume when enjoying "the love of both sexes equally"? These two series of questions have meaning only within the dominant para-

\footnotetext{
${ }^{30}$ See Marjorie Garber, Vested Interests: Cross-Dressing and Cultural Anxiety (New York: Routledge, 1992).

${ }^{31}$ Joan Nestle, "Lesbians and Prostitutes: An Historical Sisterhood," in A Restricted Country (Ithaca: Firebrand, 1987), 157-77.
} 
digm of heterosexuality/homosexuality. Because language is created by and serves the dominant class, and because Orlando's identity does not fit the dominant paradigm, there is no language for naming it. In terms of that paradigm Orlando exists outside the boundaries of language as a sexual exile. A modern reader, unless she or he is painfully obtuse, must see this identity as pansensual: Orlando's sexual identity exists independently of her sexual partners.

It is the nineteenth century that puts Orlando firmly in her place as a woman, wanting a wedding ring. Monogamy and heterosexualityand with these, restrictive gender roles-carry the day. Orlando manages to retain her identity by marrying a woman-manly man, Shel, but her days of gender-bending are over. As a mature woman of thirty-six, Orlando realizes that "nothing is any longer one thing" (305), including herself: "These selves of which we are built up, one on top of another, [are] as plates ... piled on a waiter's hand.... For she had a great variety of selves to call upon, far more than we have been able to find room for, since a biography is considered complete if it merely accounts for six or seven selves, whereas a person may well have as many thousand" (308-9). Orlando's many identities are independent of one another; they can be ordered and reordered like dishes, layered or stacked. To ascribe a single identity or a single sexuality to this character is to resort to simple reductionism. Woolf's novel can be read as nothing so narrow as lesbian, or heterosexual, or even bisexual. The amount of gender play at work here suggests that the most productive critical perspective for reading the text and the character in Orlando is the pansensual.

What conclusions can be drawn from using the lens of pansensuality (formerly bisexuality) as a comparative approach? Pansensual identity shows that the two "nations" or discourses of the heterosexual and the homosexual are in fact more alike than not in their shared, bifurcated view of sexuality. Reading Orlando from a lesbian or heterosexual feminist perspective fails to account for a multiplicity of meanings which fall outside and move beyond their discourses. A pansensual lens shows, if nothing else, that the borders of sexuality are artificial and arbitrary. Exiled from both heterosexual and lesbian nations, the pansensual feminist perspective uses a comparative approach to reconstitute its own identity, not as androgyny (man/woman) nor as bisexual (hetero/homo), but as a rejection of those very dualistic categories themselves as a meaningful way of organizing discourses of sexual identity.

Identity must be seen not as a stasis but as a movement, a plurality. In this Woolf and queer theorists span the decades of the twentieth 
century to agree. Ed Cohen writes: "If we can begin to gather together on the basis of constructions that 'we' are constantly and selfconsciously in the process of inventing, multiplying, and modifying, then perhaps 'we' can obviate the need for continuing to reiterate the fragmenting oscillations between identity and difference that have been the legacy of post 1960 s progressive politics.'"32 Ann Ferguson concurs, arguing for the need "to conceive of our goal as international political movement building (of interconnected lesbian, gay and feminist movements) rather than culture building" because "those who see themselves as building a political movement are more able to tolerate value disagreement than those who see themselves as building a culture. ${ }^{\prime \prime 3}$ Such a movement, by continually crossing boundaries of nationalisms and sexualities which challenge its exiled status, will be inherently comparative.

${ }^{32}$ Ed Cohen, "Who Are 'We'? Gay 'Identity' as Political (E)motion (A Theoretical Rumination)," in Inside/Out: Lesbian Theories, Gay Theories, ed. Diana Fuss (New York: Routledge, 1991), 88.

${ }^{33}$ Ann Ferguson, "Is There a Lesbian Culture?" in Lesbian Philosophies and Cultures, ed. Jeffner Allen (New York: State University of New York Press, 1990), 82. 
